\title{
TECNOLOGIA LASER SCANNING 3D NA PERÍCIA EM INCÊNDIOS E EXPLOSÕES
}

\author{
Lucas Bastianello Scremin ${ }^{1}$ \\ Pedro Soares de Paula ${ }^{2}$
}

\section{RESUMO}

O presente estudo teve como objetivo verificar a aplicabilidade da tecnologia de escaneamento laser tridimensional na atividade de investigação de incêndios e explosões. Trata-se de uma pesquisa do tipo aplicada e quanto à estratégia, do tipo bibliográfica e experimental, sendo coletadas informações em fontes como livros, publicações periódicas e obras acadêmicas, estabelecendo alguns tópicos importantes que devem ser levados em consideração no uso do equipamento laser scanner $3 D$ na atividade de investigação de incêndio e explosões, sendo eles; a forma de operação do equipamento, o relato do uso em um experimento prático e as possibilidades para fins didáticos. $\mathrm{Na}$ conclusão, destaca-se a relevância do equipamento para o fim proposto, dificuldades com relação aos custos do equipamento, software e computador, a gama de possibilidades de visualizações e simulações derivadas da manipulação e tratamento da nuvem de pontos gerada, além do enriquecimento do Laudo Pericial, fortalecendo o ciclo operacional de bombeiro e fornecendo informações mais completas aos órgãos e demais partes interessadas na investigação.

Palavras-chave: Investigação de incêndios e explosões. Tecnologia na investigação de incêndios e explosões. Tecnologia laser scanner 3D.

\footnotetext{
${ }^{1}$ Oficial do Corpo de Bombeiros Militar de Santa Catarina. Engenheiro Civil e Mestre em Engenharia Ambiental UFSC

${ }^{2}$ Oficial do Corpo de Bombeiros Militar de Santa Catarina. Especialista em Gestão de Riscos e Eventos Críticos, e, Perícia e Investigação de Incêndio.
} 


\title{
3D LASER SCANNING TECHNOLOGY IN FIRE AND EXPLOSION INVESTIGATION
}

\begin{abstract}
The present study aimed to verify the applicability of three-dimensional laser scanning technology in the investigation of fires and explosions. It is an applied research and as for strategy, bibliographic and experimental, being collected information from sources such as books, periodicals and academic works, establishing some important topics that must be taken into account when using laser scanner equipment. 3D in the activity of investigation of fire and explosions, being them: the form of operation of the equipment, the report of the use in a practical experiment and the possibilities for didactic purposes. In conclusion, the relevance of the equipment for the proposed purpose is highlighted, difficulties with the costs of the equipment, software and computer, the range of possibilities of visualizations and simulations derived from the manipulation and treatment of the generated point cloud, in addition to the enrichment of Expert Report, strengthening the firefighter operational cycle and providing more complete information to the agencies and other interested parties in the investigation.
\end{abstract}

Keywords: Investigation of fires and explosions. Technology in the investigation of fires and explosions. 3D laser scanner technology. 


\section{INTRODUÇÃO}

A atividade de investigação de incêndios e explosões no Corpo de Bombeiros Militar de Santa Catarina (CBMSC) ainda é incipiente e está em constante estruturação. Atualmente o que regula a tal atividade na corporação é a Diretriz de Procedimento Operacional Permanente Nr 24 (DtzPOPNr 24-17CmdoG), editada em 17 novembro de 2017, a qual estabelece em seu Art. 33 que:

Art. 33 Cabe ao Bombeiro Militar mais antigo que atuar no Combate à Incêndio a coleta de todas as informações contidas na ficha de incêndio (anexo C), incluindo-se depoimentos, e as fotografias básicas, necessárias para elucidar os fatos:

I - Fachada da edificação (frente da casa, da loja, entrada do apartamento);

II - Zona de origem (quando definido);

III - Foco inicial (quando definido);

IV - Agente causal (quando definido);

$\mathrm{V}$ - Local isolado com fita zebrada;

VI - Quadro de disjuntores.

Parágrafo único. Deve ser orientado o proprietário/responsável pela edificação sobre a importância/necessidade de não violar o local do sinistro.

O registro dos locais supramencionados pela DtzPOPNr 24-17-CmdoG, bem como a preservação do local do sinistro, são fundamentais para o bom andamento da investigação, entretanto existem uma gama de detalhes na cena de um incêndio e explosões que podem ser registrados para que no decorrer do processo possam ser reanalisados. Segundo o Guia para Investigação de Incêndios e Explosões do Corpo de Bombeiros Militar do Distrito Federal (2010), "a essência do trabalho do perito é a observação e o registro das evidências, sinalizando e fotografando as observações que julgar relevantes".

Baseada na doutrina adotada pelo Corpo de Bombeiro Militar do Distrito Federal, ametodologia para investigação de incêndios e explosões no CBMSC 
possui procedimentos para investigação de forma a orientar o Perito ou Inspetor de incêndio e explosões quais os aspectos importantes a serem observados e as ações a serem tomadas. Dentre os passos é enfatizado que seja feito o registro fidedigno do local sinistrado por meio de observação, fotos e croqui, desta forma é importante que esse registro seja o mais completo possível, para auxiliar no decorrer da investigação e, mesmo após, por solicitação de outros órgãos. O recurso utilizado costumeiramente é o registro fotográfico, o qual se limita a imagens em duas dimensões de locais considerados importantes no momento, entretanto ${ }_{2}$ atualmente dispomos de tecnologias que nos permitiriam registrar a cena com maior amplitude e precisão armazenando informações importantes que podem ser reanalisadas posteriormente.

Verifica-se que no Procedimento Operacional Padrão de Perícia Criminal do Ministério da Justiça (2013) é citado como um dos equipamentos para análise comparativa, o sistema automatizado de escaneamento.

Tal equipamento vem sendo utilizado há aproximadamente 5 anos de forma crescente internacionalmente por diversos órgãos de segurança pública na análise de cenas de crimes, acidentes veiculares ou até mesmo incêndios (LITTLE, 2018).No Brasil ainda são poucos os relatos da utilização de escaneamento à laser na investigação de incêndios e explosões, entretanto, recentemente verificou-se que a Polícia Federal utilizou o escaneamento 3D para investigar as causas do incêndio que destruiu o Museu Nacional no Rio de Janeiro em 2018 com o mesmo equipamento utilizado para realização da perícia de um acidente aéreo da empresa TAM que deixou 199 mortos em 2007 (JORNAL O GLOBO, 2018).

Conforme Marek \&Nejtková (2017), existem diversas possibilidades de utilização de um sistema de escaneamento à laser no serviço de bombeiros. Basicamente o princípio do referido escaneamento consiste em realizar, de forma rápida, automática e precisa, a detecção e captura de um grande número de pontos espaciais em um sistema de três coordenadas $\mathrm{X}, \mathrm{Y}$ e $\mathrm{Z}$. Com a 
digitalização da informação, são geradas "nuvens de pontos" que proporcionam um modelo tridimensional da cena.

Segundo Lentini (2012), a condição do local precisa ser documentada antes que $O$ investigador faça qualquer alteração. $O$ autor alerta ainda que decorrido um certo tempo após uma investigação, as fotos mais importantes não serão as que foram tiradas, mas as que não o foram, desta forma 0 escaneamento completo do local permitirá o armazenamento e a visualização posterior de uma grande quantidade de detalhes.

Como objetivo deste estudo tem-se: Verificar a aplicabilidade da tecnologia de escaneamento laser tridimensional na atividade de investigação de incêndios e explosões.

Segundo Gil (2018), trata-se de uma pesquisa aplicada a qual "abrange estudos elaborados com a finalidade de resolver problemas identificados no âmbito das sociedades em que os pesquisadores vivem". Quanto à estratégia de pesquisa, pode ser classificada, de acordo com Martins (2016), como pesquisa bibliográfica pois "busca conhecer, analisar e explicar contribuições sobre determinado assunto, tema ou problema", além de pesquisa experimental, considerando que "a experimentação é, primeiramente, um processo de observação feita em uma situação planejada de tal forma a atender à finalidade proposta".

\section{DESENVOLVIMENTO}

Serão apresentados na sequência detalhes gerais do funcionamento e aplicações dos equipamentos de escaneamento à laser relatadas por alguns autores, bem como a aplicação de um escaneamento em uma situação real de perícia em incêndio, sua forma de utilização no processo de investigação de incêndios e explosões e possíveis usos para fins didáticos.

\subsection{O EQUIPAMENTO LASER SCANNER 3D}


O laser scanner 3D é um dispositivo utilizado para a análise de objetos e/ou ambientes, coletando dados sobre forma e aparência e utilizando-os para construir modelos tridimensionais digitais. Os scanners podem ser divididos em três principais grupos: scanner 3D terrestre (estático - Figura 1a), objeto deste estudo, e scanner 3D portátil (dinâmico - Figura 1c). Outro tipo de scanner dinâmico são os instalados em aeronaves e automóveis (Figura 1b) (WIECZOREK e GÓRAWSKA, 2017).

Figura 1 - Laser scanners: a) estático; b) dinâmico em veículo aéreo não tripulado (VANT); c) dinâmico portátil

(a)

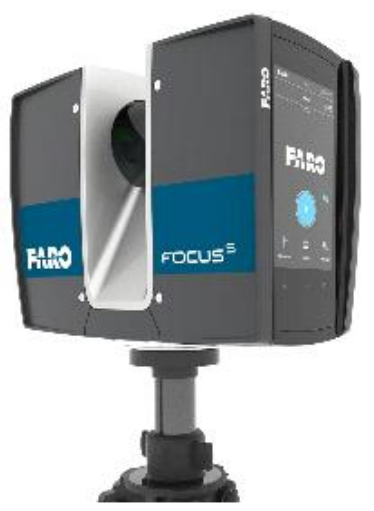

(b)

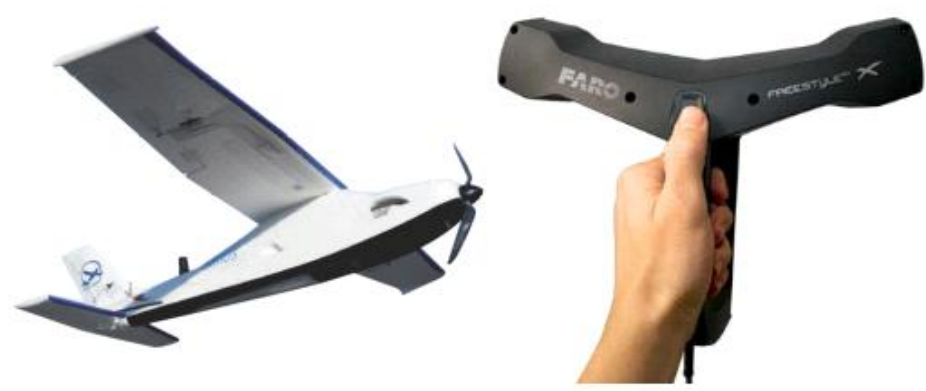

(c)

Fonte: (a) https://www.faro.com/pt-br/produtos/construction-bim-cim/faro-focus/;

(b) https://www.tecnosat.com.br/tecnosat/vant-mavinci-sirius/; (c) https://www.faro.com/pt-br/produtos/construction-bim-cim/faro-scannerfreestyle3d-x/. Acesso em 19 Março 2019.

Segundo França (2012), o equipamento foi nominado de "laser scanner 3D" considerando o uso do laser para aferição de medidas lineares e varredura horizontal e vertical para medições angulares de forma muito rápida, armazenando coordenadas nos eixos $\mathrm{X}, \mathrm{Y}$ e $\mathrm{Z}$, calculadas em tempo real. $\mathrm{O}$ equipamento proporciona giros com frequência pré-determinada e cada etapa representa um ângulo calculado em função da resolução espacial requerida. Nestes ângulos pré-determinados, tem-se os ângulos $\beta$ eae a medição $D$ 
(Figura 2). Taiscoordenadaspolaressãotransformadasemretangulares (XYZ), referenciadas e armazenadaspelo laser scanner 3D.

Figura 2 - Transformação de coordenadas polares em coordenadas $X, Y$ e Z

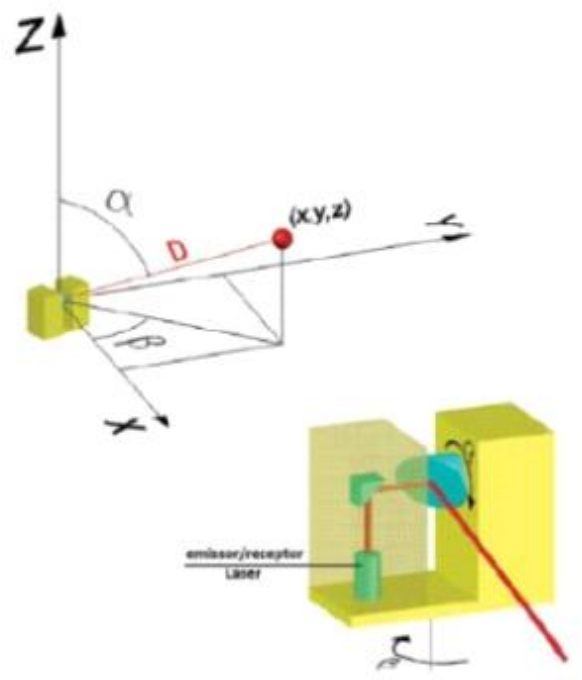

Fonte: França (2012)

Ainda conforme o autor supracitado, o prisma ou espelho reflete o laser girando no eixo vertical, controlado por um servo-motor. Simultaneamente ocorre o giro de $360^{\circ}$ do corpo do equipamento no eixo horizontal. Conforme a configuração de resolução do equipamento, o valor do giro será modificado, sendo a resolução determinada pelo espaçamento horizontal $(\mathrm{H})$ e vertical $(\mathrm{V})$ entre os pontos medidos em uma determinada distância (D) padronizada (Figura 3).

Figura 3 - Resolução horizontal e vertical

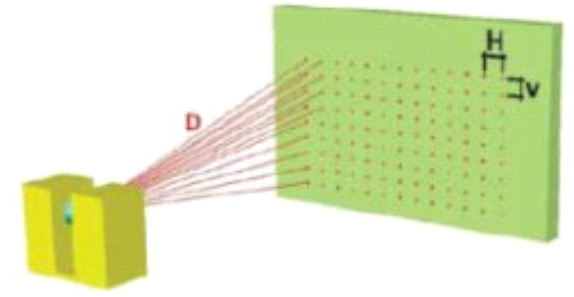

Fonte: França (2012) 
Revista Científica do Corpo de Bombeiros Militar de Pernambuco

Artigo Publicado no Vol.06 N.15 - Edição Jan a Jun 2020 - ISSN 2359-4829

Versão on-line disponível em: http://www.revistaflammae.com

Além da captura de milhares de pontos, formando a chamada "nuvem de pontos" pelo sistema automático de medição por laser rotativo, as câmeras de escaneamento a laser mais recentes usam câmera digital sincronizada para produzir uma imagem de realidade virtual 3D totalmente explorável que captura detalhes dimensionais com grande precisão (DE HAAN et al., 2011). A Figura 4 mostra um exemplo de escaneamento laser 3D de uma edificação com muitos detalhes construtivos, criando um modelo digital muito próximo do real, visto a junção feita pelas imagens captadas e a "nuvem de pontos" gerada.

Figura 4 - Exemplo de edificação digitalizada por escaneamento a laser 3D

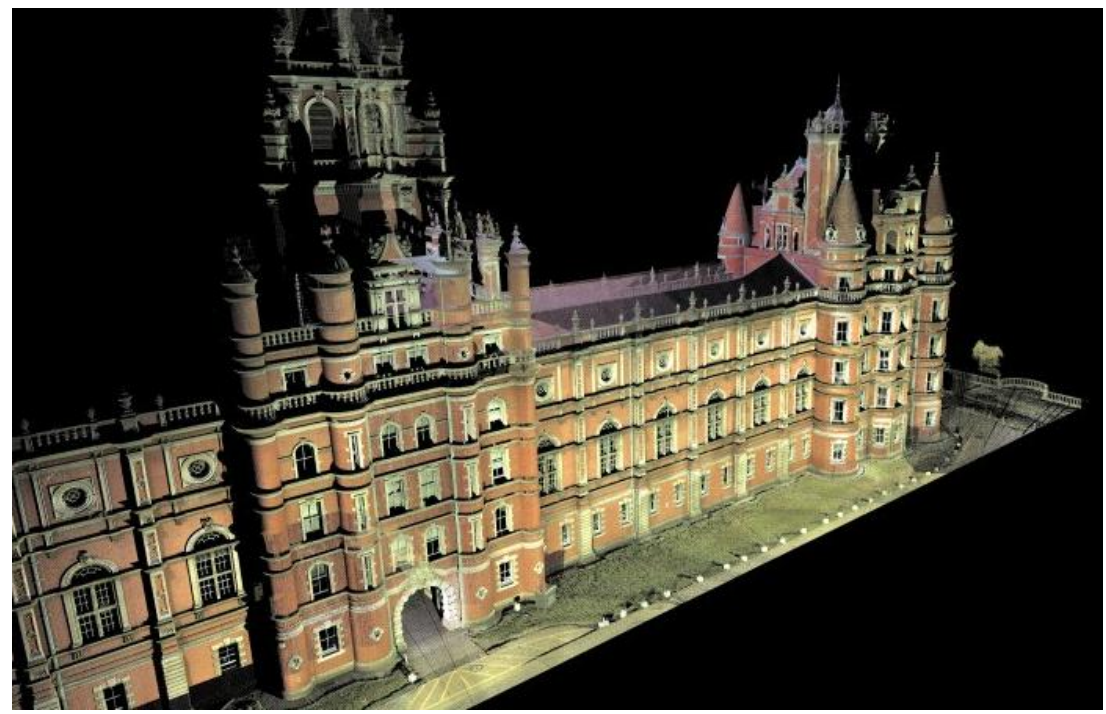

Fonte: https://www.technicsgroup.com/services/3d-laser-mapping/. Acesso em 19 Março 2019.

Quatro fatores influenciam nas exigências de precisão do equipamento utilizado - a distância dos objetos, a refletância das superfícies, a obliquidade dos ângulos de leitura e a resolução do equipamento (DODL, 2018).

Conforme Boehler, Vicent e Marbs (2003), a força do sinal de retorno do laser sofre influência, entre outros fatores (distância, condições atmosféricas, incidência e ângulo), pelas habilidades reflexivas da superfície (característica denominada de "albedo"). 
Os autores ainda trazem que:

Superfícies brancas produzirão bons reflexos, enquanto a reflexão é pobre em superfícies negras. Os efeitos das superfícies coloridas dependem das características espectrais do laser (verde, vermelho, próximo ao infravermelho). Superfícies brilhantes geralmente não são fáceis de gravar (BOEHLER, VICENT e MARBS, 2003, tradução nossa).

Bohler, Vicent e Marbs (2003) ressaltam a importância na escolha do equipamento adequado para a pesquisa a ser realizada, considerando que os resultados da mesma devem atender determinadas especificações para fornecer os padrões necessários de precisão para uma determinada aplicação. Da mesma forma, se os instrumentos e métodos utilizados produzem uma precisão muito acima do padrão necessário, isso resultará em custos e despesas desnecessários.

Segundo Wieczorek e Górawska (2017), o escaneamento à laser vem sendo utilizado em todo mundo em áreas como: arquitetura, engenharia industrial, medicina, geodésia, engenharia reversa e prototipagem, qualidade controle, inspeção e documentação de artefatos culturais, indústria de entretenimento (produção de filmes e videogames). Ele tem sido usado com sucesso na ciência forense desde o início desta década:

$\mathrm{Na}$ última década, os avanços tecnológicos tiveram um impacto significativo no trabalho dos investigadores na cena do crime. Especificamente, a tecnologia de laser 3D está permitindo que os cientistas forenses capturem representações precisas de cenas de crime e, em seguida, reconstruam virtualmente essas cenas para ajudá-las a entender melhor o ambiente e os eventos que ocorreram. A digitalização a laser 3D está a caminho de se tornar a principal forma de registro. O número de scanners que estão por aí, o número de agências que os operam, aumenta a cada ano (WIECZOREK e GÓRAWSKA, 2017, tradução nossa). 
O autor Wieczorek (2018), em seu estudo sobre a inovação nas investigações de cenas de crime utilizando scanners 3D, ressalta que a utilização mais frequente se dá nos serviços policiais dos Estados Unidos, sobretudo no exame forense de incidentes de trânsito e no local dos eventos criminais mais graves, geralmente com o uso de armas. $O$ autor relata ainda $O$ uso dos scanners 3D por órgãos de segurança pública na Europa em países como Suíça, Alemanha, Holanda, Luxemburgo, Itália e Espanha, além de outros países que tem o uso do equipamento mais incipiente.

No Brasil a utilização do equipamento de escaneamento laser 3D é menos relatada, entretanto verifica-se a aplicação em áreas de investigação forense pela Polícia Federal e alguns institutos de criminalística estaduais, além da Polícia Rodoviária Federal (PRF) que anteriormente utilizava a estação total - equipamento que também faz uso da tecnologia laser e capta pontos específicos permitindo transportar a informação para o meio digital por meio de coordenadas, entretanto com quantidade significativamente inferior de detalhamento - e nos últimos anos vem incorporando o laser scanner 3D em alguns estados do Brasil, como verifica-se em notícias publicadas (G1, 2014; JOTA, 2016; Jornalismo IFSC, 2015), além de documentos como o relatório técnico de segurança viária no 03/2016/GIAT/SE no qual utilizou-se o equipamento Scanner Faro Focus 3D (PRF, 2016).

\subsection{FORMA DE UTILIZAÇÃO NAS INVESTIGAÇÕES DE INCÊNDIO E EXPLOSÕES}

No capítulo 15 da NFPA 921(2011) - documentação da investigação - é trazido como objetivo de documentar qualquer investigação de incêndio ou explosão:

[...] registrar com precisão a investigação por meio de mídia que permitirá que os investigadores recuperem e comuniquem suas observações em uma data posterior. 
Os métodos comuns para atingir este objetivo incluem o uso de fotografias, fitas de vídeo, diagramas, mapas, sobreposições, gravações em fita, notas e relatórios.

Ainda, observa-se que no referido capítulo a fotografia com laser é citada como um tipo especial de fotografia. $\mathrm{O}$ escaneamento a laser 3D realiza diversas das funções citadas na NFPA 921 para documentação do ambiente sinistrado, tais como fotografia, vídeos (os quais podem ser feitos posteriormente estabelecendo o trajeto que se desejar), fotos sequenciais ou mosaicos de fotos - os quais tentam reproduzir o ambiente de forma mais completa (FARO, 2018). Entretanto o escaneamento a laser não substitui por completo a fotografia, visto que por vezes é necessário que seja feito o registro de alguma parte específica ou objeto no ambiente de forma mais focada e com maior resolução.

Considerando que a preservação de uma cena, envolvendo crime ou não, e das evidências forenses associadas é uma das mais importantes etapas do processo de investigação, torna-se muito importante a documentação e registro da cena do crime ou sinistro, antes de qualquer alteração, de modo a fornecer um material confiável em futuras investigações, reconstruções e experimentos (WIECZOREK, 2018).

Para fins de uso na investigação de incêndio e explosões, sugere-se que o escaneamento laser 3D seja feito anteriormente a qualquer alteração realizada pelo investigador, ainda na fase de observação do local, visto que alterações posteriores podem vir a prejudicar a reconstituição do local as found(como encontrado), não sendo raro o investigador realizar modificações no ambiente seguindo uma hipótese e posteriormente julgar a hipótese formulada como inválida, tornando inviável o retorno ao estado original encontrado. Em um segundo momento novos registros podem ser feitos em outras fases do processo de investigação, como na reconstituição do ambiente.

O modelo 3D gerado propicia aos investigadores, além da análise e observação posterior da cena, testarem as hipóteses através de pontos de 
vista de testemunhas, dinâmica de fluidos computacional e uma cena virtual com cor e escala real (RICE, 2019).

Com o uso do laser scanner é viável ainda visualizar traços que normalmente não são visíveis ao olho humano, principalmente vestígios de combustão ou traços forenses (MAREK \& NEJTKOVÁ, 2017). Outro recurso para a investigação relatado por Hancock et al. (2012) em estudo na Universidade de Nottingham, em conjunto com a Universidade de Edimburgo e Glasgow Caledonian University, é a possibilidade identificar a temperatura que o concreto foi aquecido durante um incêndio pelo retorno da intensidade da varredura laser

O escaneamento de um ambiente sinistrado ainda proporciona a utilização do modelo digital em treinamentos tanto de atuação operacional quanto de investigação em ocorrências de incêndio (WIECZOREK, 2018; RICE, 2019; MAREK \& NEJTKOVÁ, 2017).

Para que se tenha uma experiência mais imersiva da realidade virtual criada, existem acessórios que podem ser utilizados juntamente com a "vista 3D" do software, como o óculos de realidade virtual com controles e sensores (Figura 5). Desta forma o movimento realizado com a cabeça muda o ângulo de visão desejado e os controles permitem o deslocamento como se o usuário estivesse realmente dentro do ambiente.

Figura 5 - Óculos de realidade virtual VIVE HTC

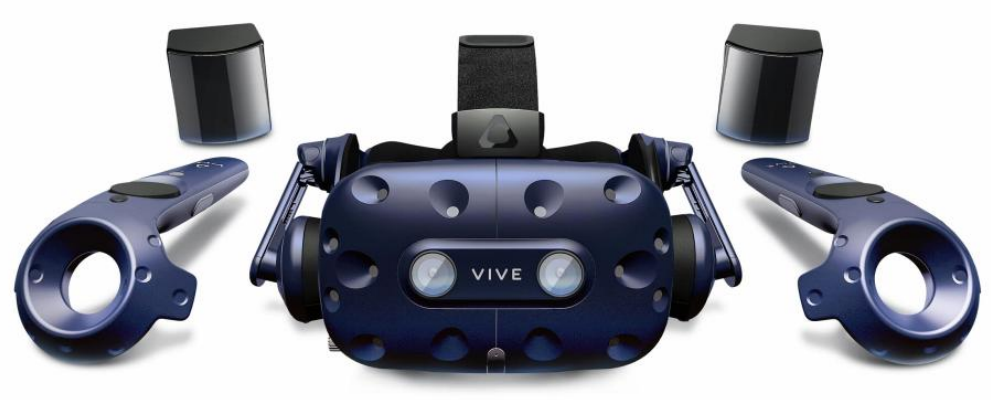

Fonte: https://www.vive.com/us/comparison/. Acesso em 20 Março 2019 
O referido equipamento de realidade virtual teria importante aplicação na atividade de instrução em investigação de incêndios e explosões fazendo com que os discentes vivenciem diferentes situações em sala de aula de uma forma muito próxima do que será visto na prática, dando a oportunidade de melhor visualizar e interpretar os vestígios encontrados em uma cena de incêndio e explosões .

\subsubsection{Operando o equipamento}

Para que seja utilizado o equipamento de escaneamento a laser 3D terrestre estático é necessário que o mesmo seja montado em um tripé, o qual pode ter diversas configurações de altura e material. Com relação à altura, é interessante que além do tripé de altura média de trabalho de 1,00 a 1,80 metros, tenha-se à disposição um tripé para baixas alturas (utilização em forros e espaços reduzidos), além de tripé com hastes alongadas.

Ao planejar qual será o posicionamento do equipamento para as varreduras a serem realizadas, deve-se levar em consideração as áreas de sombras - áreas não visualizadas pelo laser scanner por estarem obstruídas por objetos do ambiente - além da própria sombra circular abaixo do laser scanner, a qual é formada pela obstrução do corpo do equipamento (DODL, 2018).

Segundo Marek \& Nejtková (2017), em geral o processo de digitalização a partir de um único local pode levar de um minuto a até duas horas, variando em função das configurações de resolução detalhadas, entretanto com base na experiência dos autores, cada escaneamento leva cerca de 5 minutos no exterior e cerca de 3 a 4 minutos no interior de uma edificação.

O registro correto de uma varredura em relação à outra depende de pontos em comum nas duas varreduras. "Esses pontos em comum podem ser alvos naturais, alvos artificiais ou regiões sobrepostas das nuvens de pontos dos ambientes" (DODL, 2018). 
Após a coleta em campo, os dados são transmitidos para um software que varia de acordo com o modelo do laser scanner, sendo necessário um computador com boas configurações para processar os dados gerados, sobretudo nos casos em que foi utilizada uma resolução de varredura maior, ou com muitas nuvens de pontos.

Uma dificuldade encontrada e relatada por Marek \& Nejtková (2017), é com relação aos custos iniciais de hardware e software e consequente "necessidade de dispositivos de computação mais rápidos e poderosos, adequados para um vasto processamento de dados".

Com o uso do software do equipamento podem ser criados com facilidade cortes, layouts, vistas e seções de áreas de interesse, além da possibilidade de compatibilização do projeto em outros formatos que permitam utilizar softwares diversos com o intuito de modelar a estrutura, realizar simulações ou visitas virtuais (MAREK \& NEJTKOVÁ, 2017).

Para De Haan et al. (2011) "as medições de salas, portas e janelas são dados essenciais para a análise precisa e reconstrução das mais diversas cenas de incêndio". Segundo os autores deve-se buscar uma precisão de $\pm 5 \%$ em relação à dimensão real, o que é possível com o uso da tecnologia e escaneamento a laser 3D.

\subsubsection{Experimento prático}

Para realizar a aplicação do laser scanner 3D após uma ocorrência de incêndio real, optou-se por utilizar o equipamento FARO FOCUS S 150, disponibilizado para o estudo pela própria empresa fabricante, o qual possui um alcance de até $150 \mathrm{~m}$ e precisão de até $\pm 1 \mathrm{~mm}$ (FARO, 2018). O uso do referido equipamento é descrito pela fabricante em diferentes situações como reconstrução de acidentes de trânsito, apresentações 3D em tribunais, captura de cenas de crimes e incêndios (FARO, 2019). 
Conforme De Haan et al. (2011) modelos da LeicaGeosystems e da Delta Sphere (este último atualmente descontinuado) demonstraram bons resultados, mesmo em salas pequenas. Fabricado pela LeicaGeosystems, o equipamento Leica BLK360 possui um alcance máximo informado pelo fabricante de $60 \mathrm{~m}$, o que é suficiente para escaneamentos de ambientes internos ou mesmo externo, além de possuir câmera térmica integrada.

O escaneamento ocorreu em um apartamento (kitnet) de aproximadamente $20 \mathrm{~m}^{2}$, no qual houve a ocorrência de um incêndio que teve como foco inicial a geladeira e fez com que a fumaça atingisse todo $o$ apartamento e corredor comum da edificação no segundo pavimento, apesar de o incêndio ter sido controlado ainda em sua fase inicial.

Ao chegar ao local, verificou-se que o apartamento foi mantido isolado sem ter havido alterações no mesmo após a atuação da guarnição no combate.

Após análise do ambiente a ser escaneado, foram definidos cinco pontos de varredura no interior do apartamento e três no corredor, que também foi atingido pela fumaça decorrente do incêndio. Foi utilizado como parâmetro do escaneamento um perfil já pré-determinado no aparelho "interno até $10 \mathrm{~m}$ ", o qual tem configurado uma resolução $1 / 8$ e qualidade $3 x$,capturando assim mais de 10 milhões de pontos em cada varredura. Ainda, o parâmetro Distância pontual[mm/10m], foi de 12.272 , o que significa que pontos capturados de um plano a $10 \mathrm{~m}$ de distância do laser scanner estarão distantes 12.272 mmum do outro. Algumas varreduras foram realizadas também usando o recurso de fotos do aparelho e outras sem. O tempo para as varreduras com fotos foram de aproximadamente cinco minutos, enquanto sem fotos, dois minutos.

Finalizados os escaneamentos, os arquivos digitais foram passados para 0 computador e processados com o uso do software FAROScene 7.1. Na figura 6 , tem-se um croqui da situação (apartamento kitnet) gerado pelo software Scene, onde os pontos da varredura estão marcados em azul. 
Figura 6 - Croqui do local

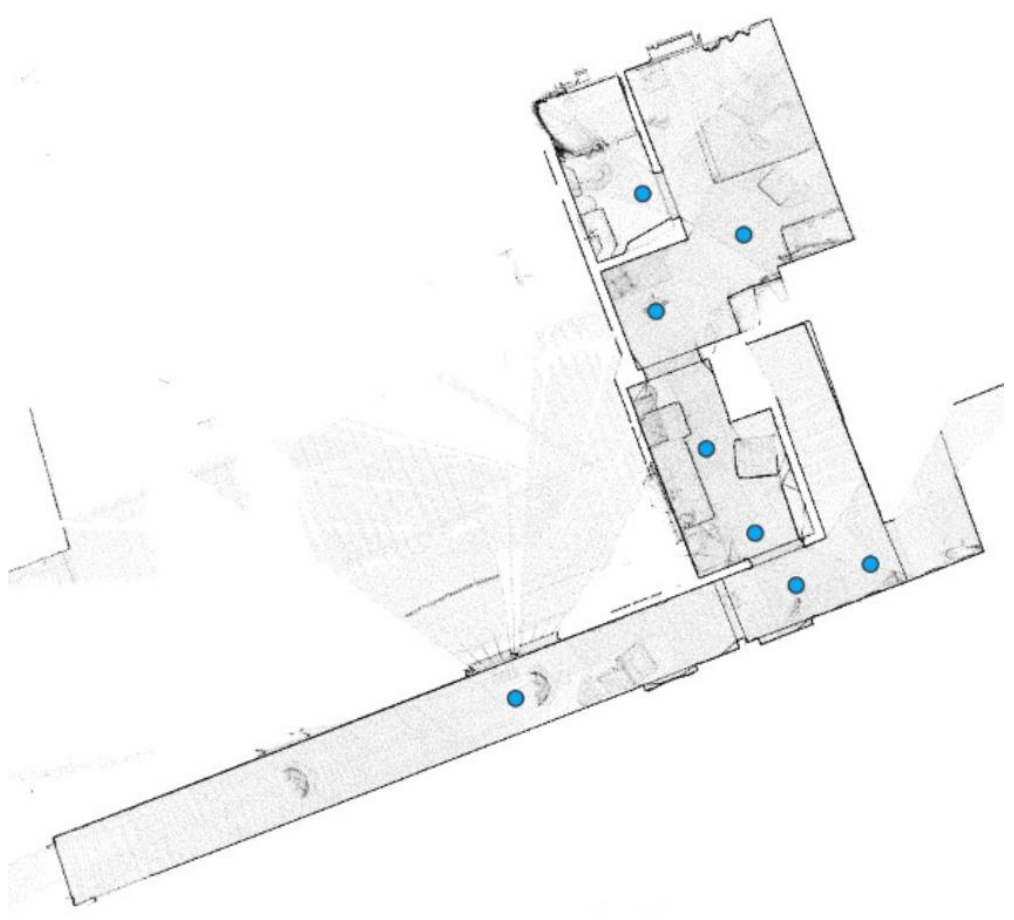

Fonte: Os autores (2019).

Para operar o programa e utilizar de todas suas funcionalidades não é necessário que o usuário tenha conhecimento aprofundado na área da computação ou engenharias, entretanto, o passo a passo para a correta operação pode ser encontrado no Manual do Usuário (FARO, 2018) do Scene, ou também de forma bastante explicativa no estudo realizado por Dodl (2018). $\mathrm{Na}$ figura 7, uma visão geral do software Scene $7.1 \mathrm{com}$ a imagem do ponto de vista de uma das cenas. 
Revista Científica do Corpo de Bombeiros Militar de Pernambuco

Artigo Publicado no Vol.06 N.15 - Edição Jan a Jun 2020 - ISSN 2359-4829

Versão on-line disponível em: http://www.revistaflammae.com

Figura 7- Software FARO Scene com a zona de origem do ponto de vista do scanner

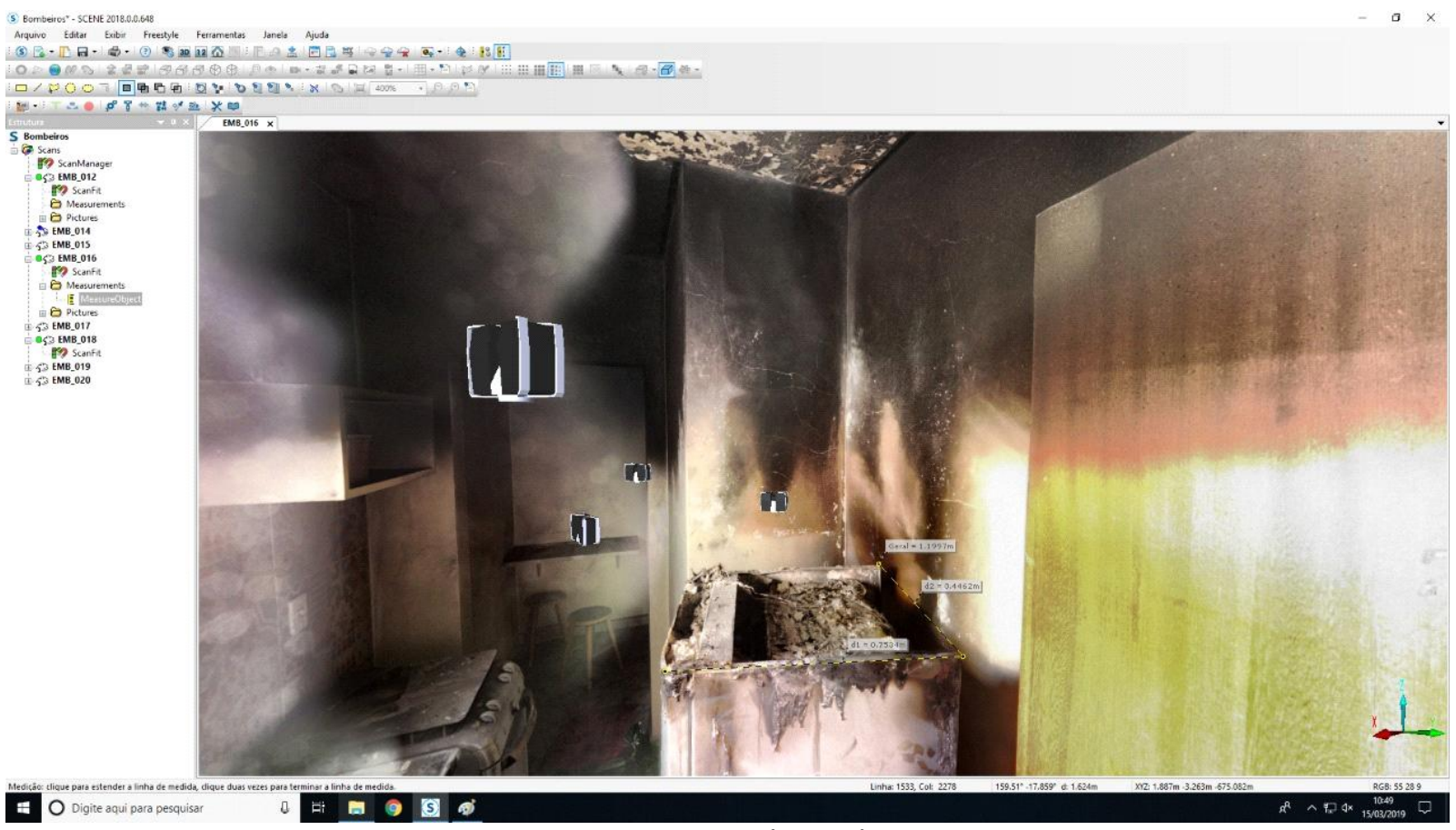

Fonte: dos autores (2019)

Observou-se que em qualquer posição que a visualização esteja, é possível realizar medições compatíveis com a realidade, além da possibilidade de gerar o croqui de situação (conforme figura 5). Para a confecção de uma planta baixa mais detalhada, faz-se necessária a exportação da nuvem de pontos para ser tratada em um software de desenho, como por exemplo, o AutoCad ou similar.

Como produto dos registros realizados, podemos ter a visualização $360^{\circ}$ do ponto de vista do scanner em cada varredura, - podendo percorrer toda a nuvem de pontos sem limitação no deslocamento pelo ambiente. É possível ainda gerar vídeos de trajetos pelo ambiente ${ }^{3}$ ou utilizar o aplicativo FARO

\footnotetext{
${ }^{3}$ No seguinte link é possível visualizar um vídeo gerado pela digitalização a laser 3D em uma casa pós incêndio: <https://pt.insights.faro.com/public-safetyforensics/digitalizacao-a-laser-3d-em-casa-com-danos-causados-pelofogo>
} 


\section{Revista FLAMMAE}

Revista Científica do Corpo de Bombeiros Militar de Pernambuco

Artigo Publicado no Vol.06 N.15 - Edição Jan a Jun 2020 - ISSN 2359-4829

Versão on-line disponível em: http://www.revistaflammae.com

Scene $2 \mathrm{Go}^{4}$ (Figura 8-A) para compartilhar o resultado e permitir que 0 "projeto" possa ser visualizado por meio navegador de internet, permitindo além da visualização de cada cena, a realização de medições de distâncias e cálculo de áreas áreas, conforme pode ser visto na figura 8-B.

Figura 8 - FARO Scene 2 Go - Vista de abertura do projeto (A) e visualização
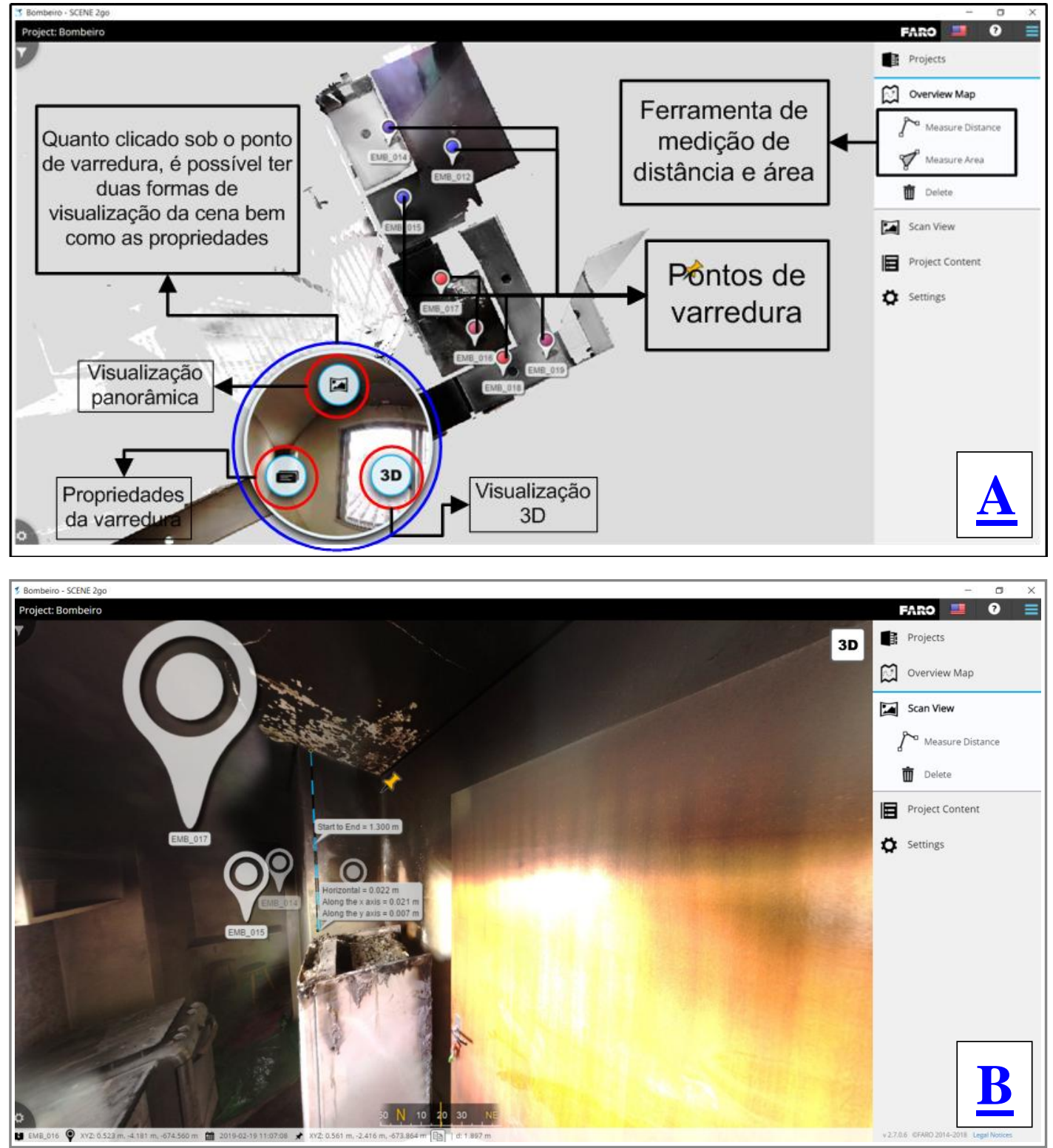

Fonte: Resultados da Pesquisa (2019)

\footnotetext{
${ }^{4}$ Acessando o link

<https://drive.google.com/file/d/18stDYKK4U5ekgH7Gf7eNWOlohJxiyl4J/view?usp=sharing > é possível ter acesso ao SCENE $2 \mathrm{GO}$ e utilizar a ferramenta.
} 


\section{CONCLUSÃO}

Com o presente estudo, pôde-se relatar a forma de funcionamento e aplicação dos equipamentos de escaneamento a laser 3D, o qual em geral realiza uma varredura de todo o ambiente, processa e gera nuvens de pontos tridimensionais.

Verificou-se a importância do estudo prévio das necessidades para o uso do equipamento de forma que seja escolhido o equipamento adequado e gastos desnecessários sejam evitados.

Uma dificuldade encontrada para a aquisição do equipamento é o custo do laser scanner $3 D$, seu software e computador com boas configurações para o processamento dos dados, tornando onerosa a aquisição e disponibilização do equipamento para todas as regiões, entretanto, com somente um equipamento (podendo ser compartilhado entre os Batalhões Bombeiro Militar) seria possível a utilização em diversas ocorrências de vulto ou mais complexas que necessitem de uma análise posterior detalhada.

Há ainda a possibilidade de utilização dos modelos digitais de ambientes sinistrados por um incêndio ou explosão para fins didáticos. Permitindo também o uso de óculos de realidade virtual para a imersão dos discentes em uma situação muito próxima da real.

O custo ainda elevado é justificado por se tratar de uma tecnologia que vem sendo desenvolvida na última década, e com uso crescente relatado em diversos países, sobretudo da Europa e América do Norte. É natural que com o passar dos anos os custos sejam reduzidos e a tecnologia torne-se mais acessível.

O equipamento mostrou-se importante no registro da cena antes de qualquer alteração realizada, seja por populares ou pelo próprio investigador. Sua operação é simples, sendo necessária a busca por um maior 
conhecimento por parte do operador na etapa de processamento digital dos dados.

Alguns resultados derivados da manipulação da nuvem de pontos foram relatados, tais quais visualizações diversas (cortes, vistas, seções de áreas), vídeos de trajeto no interior ou exterior do ambiente, vista 3D podendo caminhar pelo ambiente, compartilhamento das vistas 3D com visualização pela internet e simulações diversas com o uso de outros softwares.

Conforme evidenciado no decorrer deste estudo, a tecnologia laser scanning $3 D$ vem a contribuir com o processo de investigação de incêndios e explosões, bem como a atividade de ensino, considerando os diversos recursos que ela proporciona, fornecendo de forma técnica muitos detalhes da ocorrência investigada e permitindo o armazenamento, consulta e fornecimento de informações posteriores precisas a diversos órgão e partes interessadas, além de potencializar a retroalimentação do sistema, contribuindo para o fechamento do ciclo operacional de bombeiro.

\section{REFERÊNCIAS}

BOEHLER, W.; VICENT, M.B.; MARBS A..Investigating Laser Scanner Accuracy. I3mainz, Institute for SpatiallnformationandSurveying Technology, FH Mainz, Holzstrasse 36, 55116 Mainz, Germany, 2003.

CORPO DE BOMBEIROS MILITAR DO DISTRITO FEDERAL. Guia de investigação de incêndio. Distrito Federal, 2010. Disponível em: $<$ https://www.cbm.df.gov.br/2012-11-12-17- 41-39/investigacaoincendio?view=document\&id=1336>. Acesso em: 26 fev. 2019.Brasil.

DE HAAN, John D. et al. Kirk'sfireinvestigation. Pearson Higher, 2011.

\section{Diretriz de Procedimento Operacional Permanente Nr 24-CmdoG.} Florianópolis: CBMSC, 23 nov. 2017.

\section{DODL, L.D. Caderno de Boas Práticas para As-Is BIM Usando Laser}

Scanner FARO e Revit. Trabalho de Conclusão de Curso (Engenharia Civil) Instituto Federal de Santa Catarina (IFSC). Santa Catarina, p. 104. 2018. Disponível em: <https://repositorio.ifsc.edu.br/handle/123456789/344>. Acesso em: 11 de março de 2019. 
FARO. Manual do Usuário do Faro Laser Scanner. Versão novembro de 2018. Disponível em:

<https://faro.app.box.com/s/dti4ov9e4xt62yrh3m8uqqwgtl8zgqx8/file/40570199

0950 >. Acesso em: 15 de dezembro de 2019.

FARO. Análise forense ou planejamento pré-incidente.Disponível em:<https://pt.insights.faro.com/public-safety-forensics>. Acesso em: 15 de dezembro de 2019.

FRANÇA, Rovane Marcos de. Milhões de pontos: Conheça mais sobre o laser scanner terrestre em três dimensões. MundoGEO: A revista de geomática e soluções geoespaciais, Curitiba, v. 1, n. 67, p.68, mar. 2012. Bimestral.

GIL, A. C. Como elaborar projetos de pesquisa. $6^{a} \stackrel{e}{e}$. - São Paulo: Atlas, 2018.

G1, Polícia do Acre recebe laser scanner 3D de Israel para otimizar perícia. Disponível em: <http://g1.globo.com/ac/acre/noticia/2014/06/policia-doacre-recebe-laser-scanner-3d-de-israel-para-otimizar-pericia.html>. Acesso em: 20 de março de 2019.

HANCOCK, C. M.; ROBERTS, G. W.; BISBY, L.; CULLEN, M.; ARBUCKLE, J..DetectingFireDamaged Concrete Using Laser Scanning.FIG Working Week 2012. Knowingtomanagetheterritory, protecttheenvironment, evaluatethe cultural heritage. Rome, Italy, 6-10 May 2012.

Jornal O Globo, PF usa scanner 3D nas investigações do incêndio do Museu Nacional. Disponível em: <https://oglobo.globo.com/rio/pf-usa-scanner3d-nas-investigacoes-do-incendio-do-museu-nacional-23039877>. Acesso em: 4 de fevereiro de 2019.

JOTA INFO, Governo entregou cinco dos 22 scanners de fiscalização prometidos à PRF. Disponível em:

<https://www.jota.info/paywall?redirect_to=//www.jota.info/justica/governoentregou-apenas-cinco-dos-22-scanners-de-fiscalizacao-de-veiculos-para-prf03032016 >. Acesso em: 20 de março de 2019.

LENTINI, John L. Scientificprotocols for fireinvestigation. EUA. Taylor \& Francis Group: 2013.

LINK DIGITAL - IFSC, Realizada solenidade de abertura do curso de especialização em parceria com a PRF. Disponível em:

$<$ https://inkdigital.ifsc.edu.br/2015/10/29/realizada-solenidade-de-abertura-docurso-de-especializacao-em-parceria-com-a-prf/>. Acesso em: 20 de março de 2019. 
LITTLE, Darwin. Using 3D Laser Scanners in Crime Scenes:Understanding Advantages and Disadvantages. Weber StateUniversity, 2018. Disponível em:

https://apps.weber.edu/wsuimages/BIS/PrimaryResearch/Darwin\%20Little\%20 BIS\%20Final\%20Paper\%202018\%20(3).pdf. Acesso em: 28 de junho de 2019.

MARTINS, G. A. Metodologia da investigação científica para ciências sociais aplicadas. $3^{\underline{a}}$ ed. - São Paulo: Atlas, 2016.

NATIONAL FIRE PROTECTION ASSOCIATION et al. NFPA 921: Guide for Fire and Explosion Investigations. National Fire Protection Association, Quincy, 2011.

RICE, R.E. 3D Scans\&UAVs. Maltase Fire Investigation, Washington D. C., 2019. Disponível em: <http://www.maltasefire.com/projects.html>. Acesso em: 10 mar 2019.

SECRETARIA NACIONAL DE SEGURANÇA PÚBLICA. Procedimento operacional padrão: perícia criminal/ Secretaria Nacional de Segurança Pública. Brasília: Ministério da Justiça, 2013. 242p.: il.

T. WIECZOREK. Innovativeinvestigationsofthe crime sceneusing 3D Scanners. Internacional Scientific Journal "Security \& Future". YEAR II, ISSUE 1, P.P. 39-42, 2018.

WIECZOREK, T.; GÓRAWSKA, A.. Portable 3D Scanners for Crime Scenelnvestigation. Studia Informatica. Volume 38. Number 3 (132), Poland 2017.

ZdeněkMAREK ,Miroslava NEJTKOVÁ. Use of a laser scanning system for professional preparationandscene assessment offirerescueunits.

Transactionsof the VSB - Technical universityof Ostrava. Vol. XII, No. 1, 2017. 